\title{
IMAGING SPECTROPHOTOMETRY OF THE RING NEBULA
}

\author{
NANCY JO LAME and RICHARD W. POGGE \\ The Ohio State University \\ Columbus $\mathrm{OH}$ 43210, USA
}

We present new results from a program of emission-line imaging spectrophotometry of planetary nebulae using the Ohio State University Imaging Fabry-Perot Spectrograph (IFPS). High-quality emission-line maps of the important diagnostic lines [NII] $\lambda \lambda 5755,6583$, [SII] $\lambda \lambda 6717,6731,[\mathrm{OI}] \lambda 6300,[\mathrm{OIII}] \lambda 5007, \mathrm{H} \alpha$, and $\mathrm{H} \beta$ have been obtained. Maps of the ionization structure $([\mathrm{S} \mathrm{II}] / \mathrm{H} \alpha,[\mathrm{N} \mathrm{II}] / \mathrm{H} \alpha,[\mathrm{O} \mathrm{III}] / \mathrm{H} \beta$, and $\left.[\mathrm{O} \mathrm{I}] /\left[\begin{array}{ll}\mathrm{O} & \mathrm{III}\end{array}\right]\right)$, temperature in the $\mathrm{N}^{+}$region, density in the $\mathrm{S}^{+}$region, and Balmer decrement across the nebula are presented. These show considerable variation in ionization state, temperature and density. This detailed information will provide powerful constraints on photoionization models for the Ring Nebula. 